\title{
HISTÓRIA DE LINO: A PSICOPATOLOGIA NA PERSPECTIVA DA FENOMENOLOGIA E DO EXISTENCIALISMO
}

\author{
Lino's Story: Psychopathology from the Perspective of Phenomenology and Existentialism \\ Historia de Lino: la psicopatología desde la perspectiva de la fenomenología y el existen-
cialismo
}

Resumo: A partir dos anos 1950-1960 constituíram-se iniciativas, na Europa, para uma ruptura do modelo psiquiátrico hegemônico vigente até então, consolidando a antítese à lógica psiquiatrizante que se caracteriza enquanto uma psicopatologia crítica. Por meio dela, alguns psiquiatras passaram a adotar uma postura compreensiva frente ao adoecimento psíquico, em detrimento de uma busca por causalidades, entendendo o sofrimento como resultado da construção de uma personalidade no mundo. A pesquisa base deste artigo objetivou a compreensão fenomenológica e existencial da psicopatologia de Lino, um homem adulto diagnosticado com transtorno esquizoafetivo. Foi utilizado método qualitativo caracterizado como história de vida, tendo sido realizadas entrevistas narrativas para coleta de dados e empregada análise da narrativa para a composição dos resultados e discussões. Nas análises, constatou-se um processo de divisão do ser, forjado por forças sociológicas contraditórias e que constituíram a base da psicopatologia de Lino. Neste sentido, a entrada na loucura pode ser considerada como um corte com a rede de relações concretas e simbólicas significativas do sujeito e consequente perda do sentido da realidade. Pensar a psicopatologia em uma perspectiva crítica implica, assim, pensar o sujeito na totalidade de suas relações e na apropriação que faz das mediações ao longo de sua biografia. Palavras-chave: Psicologia; Psicopatologia; Fenomenologia; Existencialismo; Biografia.

\begin{abstract}
From the 1950s-60s onwards in Europe, initiatives for a rupture with the existing hegemonic psychiatric model were established, consolidating an antithesis to the psychiatrizing logic, which can be characterized as a critical psychopathology. Thereby, some psychiatrists began to adopt a comprehensive attitude towards psychic illness instead of searching for causalities, understanding suffering as the result of the construction of a personality. The research on which this article was based aimed at a phenomenological and existential understanding of Lino's psychopathology, an adult man diagnosed with schizoaffective disorder. The life-history method was applied, several interviews were conducted for data collection, and narrative analysis was used to prepare results and discussions. In the analyses, a process of division of the being was found, forged by contradictory sociological forces, which were the basis of Lino's psychopathology. In this sense, the beginning of madness may be considered as a break with the subject's network of concrete and significant symbolic relationships and the consequent loss of his sense of reality. Therefore, thinking psychopathology from a critical perspective implies understanding subjects in their relationships as a whole, with the appropriation of mediations they do throughout their biography.
\end{abstract}

Keywords: Psychology; Psychopathology; Phenomenology; Existentialism; Biography.

Resumen: A partir de los años 1950-1960 en Europa se han tomado iniciativas para una ruptura del modelo psiquiátrico hegemónico vigente hasta aquel momento, consolidando una antítesis a la lógica psiquiatrizante, que se caracteriza como una psicopatología crítica. A través de ella, algunos psiquiatras han adoptado una actitud comprensiva frente a la enfermedad mental, en lugar de una búsqueda de causalidades, entendiendo el sufrimiento como resultado de la construcción de una personalidad. La investigación base de este artículo tuvo como objetivo la comprensión fenomenológica y existencial de la psicopatología de Lino, un hombre adulto con diagnóstico de trastorno esquizoafectivo. Fue utilizada la metodología de la historia de vida, con entrevistas para recolección de datos y la utilización del análisis narrativo para componer las discusiones. En los análisis, se ha constatado un proceso de división del ser, forjado por fuerzas sociológicas contradictorias, que constituyen la base de la psicopatología de Lino. En este sentido, el comienzo de la locura puede ser visto como una ruptura con la red de relaciones concretas y simbólicas del sujeto y la consecuente pérdida del sentido de realidad. Pensar la psicopatología en una perspectiva crítica supone comprender el sujeto en todas sus relaciones y en la apropiación que hace de las mediaciones en toda su biografía.

Palabras clave: Psicología; Psicopatología; Fenomenología; Existencialismo; Biografía. 


\section{Introdução}

As teses psiquiátricas que ganharam hegemonia na contemporaneidade consideram os chamados "transtornos mentais" como tendo determinação orgânica, sendo tomados em uma perspectiva individual. Partindo de uma concepção naturalizante do que seriam as "doenças mentais", a psiquiatria descritiva não discute a relação de determinação de sua ocorrência com as relações sociais, preocupando-se mais em descrever seus sintomas para então suprimi-los (Serpa Junior; Leal; Louzada; Silva Filho, 2007; Schneider, 2009).

De modo geral, o diagnóstico destas ditas doenças mentais é realizado com a utilização do Manual Diagnóstico e Estatístico de Transtornos Mentais (DSM), atualmente em sua quinta versão ${ }^{1}$, elaborado por psiquiatras que listam categorias de transtornos mentais e critérios para diagnosticá-los de acordo com a Associação Americana de Psiquiatria (2014), e a Classificação Estatística Internacional de Doenças e Problemas Relacionados com a Saúde (CID 10) (Organização Mundial de Saúde, 1993). Ambos são utilizados por profissionais de saúde e oferecem uma descrição precisa a respeito do conjunto de sintomas das psicopatologias, sintomas estes que não deixam de ser constatáveis, mas que, ao serem identificados, não necessariamente contribuem para a compreensão de como a psicopatologia chegou a se constituir para aquele sujeito, nem providenciam indicações para a superação da mesma senão principalmente pela via medicamentosa (Schneider, 2009).

Dentro dos parâmetros da psiquiatria contemporânea, por vezes é possível verificar uma preocupação do clínico em contextualizar a ocorrência dos sintomas vivenciados pelo sujeito. Porém esta contextualização está com frequência mais relacionada com a busca por critérios seguros para realizar diagnósticos precisos do que para a compreensão do sujeito como um ser que se constitui nas relações e da psicopatologia enquanto uma saída forjada pelo sujeito para o enfrentamento de uma situação insuportável (Serpa Junior; Leal; Louzada; Silva Filho, 2007; Schneider, 2009). Nesta direção, numa avaliação diagnóstica, depois das informações levantadas pelo clínico, a tarefa passa a ser determinar se o sujeito satisfaz os critérios para um ou mais transtornos psiquiátricos de acordo com o DSM (American Psychiatric Association, 2014). Geralmente as informações são levantadas por meio de entrevistas que auxiliam o clínico nos diagnósticos diferenciais, tendo este como tarefa fazer os diagnósticos de acordo com o disposto no manual, ou seja, de acordo com o preenchimento de uma lista de critérios em relação à presença ou não de sintomas

\footnotetext{
1 A primeira edição do Manual Diagnóstico e Estatístico de Transtornos Mentais (DSM) foi publicada em 1953. DSM e CID-10 são nosográficos e visam à classificação dos transtornos mentais, sendo ambos sistemas categoriais. Em sua apresentação, o DSM refere que tenta ser neutro em relação às teorias etiológicas, evidenciando seu "descompromisso teórico" (Schneider, 2009).
}

(Sadock \& Sadock, 2011).

Esta lógica diagnóstica com base na identificação e descrição de sintomas compreende a "doença mental” enquanto entidade mórbida, sem que se questione as condições de possibilidade de ocorrência dos fenômenos psicopatológicos (Schneider, 2009). Foi então Karl Jaspers o primeiro psiquiatra fenomenólogo, que já no início do século XX, com sua obra Psicopatologia Geral (1913/1987), propôs que a psiquiatria deveria ocupar-se da pessoa como um todo, entendendo que seus limites consistem em jamais poder reduzir o sujeito a conceitos psicopatológicos. Propondo que a doença realiza-se no núcleo da existência, Jaspers (1987) definiu que "compreender” indica o entendimento do psíquico adquirido por dentro da história do sujeito, rompendo com a visão exclusivamente explicativa realizada "por fora” e com base em conexões causais propostas pela psiquiatria até então descritiva.

Jean Paul Sartre, filósofo e escritor francês, foi influenciado por esta compreensão de Jaspers sobre a psicopatologia. Conforme descreve Schneider (2017), Sartre, durante sua formação como filósofo e nos anos subsequentes, demostrou interesse pelo campo da psicopatologia, mantendo contato próximo com psiquiatras, psicanalistas e psicólogos clínicos, tendo realizado debates sobre psicanálise e problemáticas psicológicas com J. B. Pontalis, psicanalista e companheiro na revista Les Temps Modernes. Mas foi principalmente a partir da contribuição de Sartre para a tradução do livro "Psicopatologia Geral” de Jaspers para o francês, quando era ainda estudante de filosofia, que esta concepção de psicopatologia teve impacto no pensamento sartreano (Schneider, 2017).

Em seu livro A força da Idade (1960), Beauvoir cita o encontro de Sartre com os escritos de Jaspers:

À psicologia analítica e empoeirada que ensinavam na Sorbonne, ele (Sartre) desejava opor uma compreensão concreta, logo sintética dos indivíduos. Essa noção, ele tinha encontrado em Jaspers, cujo tratado de psicopatologia, escrito em 1913, fora traduzido em 1927; corrigira as provas do texto francês com Nizan. Jaspers opunha à explicação causal, utilizada nas ciências, outro tipo de pensamento que não se assenta em nenhum princípio universal, mas que apreende relações singulares, mediante intuições, mais afetivas do que racionais e de irrecusável evidência; ele a definia e justificava a partir da fenomenologia. Sartre ignorava tudo dessa filosofia, mas nem por isso deixara de reter a ideia de compreensão e de tentar aplicá-la (Beauvoir, 1960, p. 52-3).

Já Laing e Cooper, em seu livro Razão e Violência, descrevem falas do próprio Sartre a respeito do encontro do existencialista com a perspectiva compreensiva de Jaspers: 
Também eu julgo que não se pode compreender as perturbações psíquicas do exterior, a partir de um determinismo positivista, nem reconstruí-las graças a uma combinação de conceitos que permanecem externos à doença. Creio também que não se pode estudar ou curar uma neurose sem o respeito original à pessoa do paciente [...] julgo a 'doença mental' como uma saída que o organismo livre, em sua unidade total, inventa para poder viver uma situação insuportável. [...] e estou convicto de que seus esforços [de Laing e Cooper] contribuem para acelerar a aproximação do tempo em que a psiquiatria será, finalmente, humana (Sartre citado por Laing; Cooper, 1982, p. 7).

A psiquiatria fenomenológica de Jaspers, portanto, influenciou fortemente a proposta de Sartre (1943/1997) de que o ponto de partida da investigação do sofrimento deve ser os aspectos concretos de sua vida, tendo em vista que o desenvolvimento das psicopatologias está diretamente relacionada à constituição de uma personalidade (Jaspers, 1979; Schneider, 2017). Confome destaca Schneider (2017), este empreendimento realizado por Sartre pode ser verificado no conjunto de sua obra, mas mais especificamente na proposta metodológica denominada "Psicanálise existencial" (Sartre 1943/1997), em seu texto Questão de Método (Sartre, 1945/1978) e em seus empreendimentos biográficos, em especial na biografia de Flaubert (Sartre, 1971/2015).

Depois de Jaspers, a partir dos anos 1950-1960 com o movimento antipsiquiátrico surgido na Europa, especialmente na Inglaterra, França, Itália e também nos Estados Unidos, constituíram-se iniciativas cujo objetivo era promover uma ruptura com o modelo psiquiátrico hegemônico até então, consolidando a antítese à lógica psiquiatrizante e que se caracteriza enquanto uma psicopatologia crítica. Por volta desses anos começou-se a questionar a noção de saúde mental predominante à época, bem como as formas de tratamento, criticando a desumanização e a pouca efetividade das ações psiquiátricas (Spohr \& Schneider, 2009, Spohr, 2011).

Assim, alguns psiquiatras contemporâneos a Sartre, entre eles Jan Hendrik Van Den Berg, Ronald Laing, Franco Basaglia e David Cooper, passaram a adotar uma postura compreensiva frente ao adoecimento psíquico, tendo inclusive como base a teoria existencialista de $\mathrm{Sartre}^{2}$, entendendo que o sofrimento ocorre como resultado de um processo de construção de uma personalidade no mundo e em meio às relações. Começou-se então a adotar uma

\footnotetext{
2 Em entrevista a Vicary, Sartre foi por ele questionado sobre "O que você disse de relevante para mudar a psiquiatria?", quando sua resposta foi: "Penso que os antipsiquiatras estavam procurando uma teoria na qual a liberdade pudesse ser colocada em primeiro lugar, dessa forma a doença mental, ou melhor, aquilo que se chama de doença mental, pudesse aparecer como um aspecto da liberdade humana e não como uma doença resultante de um mau funcionamento do cérebro ou de alguma doença física" (Sartre citado por Charlesworth, 1980).
}

oposição à noção de doença mental sustentada em uma perspectiva mecanicista e de base neurofisiológica, que não só inviabilizava a compreensão do fenômeno "adoecimento psíquico" na sua totalidade, como também impedia o sujeito de emancipar-se de seu "rótulo", já que ele era entendido como oriundo de "problemas internos" (Schneider, 2009).

Neste sentido, conforme afirma Schneider (2011, 2017), em uma perspectiva existencialista, a psicopatologia deve ser compreendida como fenômeno, composta por variáveis constitutivas e determinantes, sendo as variáveis constitutivas os diferentes aspectos constituintes das psicopatologias, que as delimitam e as definem (questões orgânicas, por exemplo); e as determinantes as ocorrências externas a este fenômeno, dado que o desencadearam ou alteraram sua evolução regular, possibilitando compreender as condições de possibilidade para sua ocorrência, estando sempre situadas no contexto antropológico e sociológico dos sujeitos.

O que é fundamental nesta lógica é a compreensão de que as determinantes do enlouquecimento são sócio-históricas e que o aspecto psicológico é que constitui sua variável fundamental, que possibilita sua definição e por isso chama-se psicopatologia. O sofrimento é algo que se constitui nas relações e, portanto, dentro de um campo sociológico (relações de mediação para o sujeito) que, por sua vez, está inserido em um determinado campo antropológico (condições materiais, produtivas, ideológicas, etc.). A loucura não acomete o sujeito como uma entidade mórbida, mas se constitui enquanto processo (Schneider, 2011).

Esta concepção de psicopatologia é possível a partir da compreensão de que o sujeito é um "ser-no-mundo", um ser psicofísico - corpo e consciência-, através e pelos quais se relaciona com a exterioridade, estabelecendo relações que caracterizam sua existência. A partir do estabelecimento das relações com os outros, que irão mediar suas relações com as coisas, com o tempo e com seu próprio corpo, é que o sujeito terá possibilidades de construir sua personalidade. Assim, o sujeito age no mundo e depois se apropria da sua ação a partir do que possui enquanto mediação e condição para a compreensão do seu fazer (Sartre, 1978).

Portanto, as complicações psicológicas são compreendidas enquanto um modo de relação do sujeito com o mundo, com os outros, com ele mesmo, implicando o enredamento de uma personalidade. Segundo Schneider (2011) a complicação psicológica é um acontecimento concreto na vida do sujeito, resultado da dialética entre condições objetivas e possibilidades subjetivas, que limitam o campo de possibilidades o levam a experimentar uma contradição de ser, pois a realidade lhe apresenta diferentes possibilidades e seja qual for o lado para o qual se dirigir, seu ser está comprometido.

Sentindo-se pressionado a escolher diante dessas contradições, o sujeito pode experimentar-se 
com dificuldades para superá-las, de modo que seu projeto de ser futuro fique ameaçado ou comprometido. Esta experiência ocorre em nível de corpo e consciência, afetando as emoções e os desejos do sujeito e que, naquele momento, coloca todo o seu ser em questão. A escolha que o sujeito fizer nesta situação, portanto, terá necessariamente implicações em seu projeto de ser. Assim, a complicação psicológica passa pela insegurança na realização do projeto, ou ainda, pela inviabilização do projeto e do desejo de ser (Schneider, 2011, Spohr, 2011).

Em relação à noção de projeto de ser, Sartre (1997) esclarece que as ações humanas nunca são fortuitas, pois o ser humano está ontologicamente impossibilitado de ser um punhado de fatos isolados. Os sujeitos são, portanto, sempre voltados para o futuro e toda e qualquer ação, necessariamente constitutiva de seu ser, forma parte de uma totalidade, que vem a ser o projeto de ser ou projeto original. Neste sentido, na realidade humana, toda ação necessariamente se articula com a totalidade do ser e todo ato é significativo, não se limitando a si mesmo, remetendo-se sempre a uma eleição mais ampla de um mundo porvir.

Assim, toda complicação psicológica poderá ser compreendida na medida em que seja possível conhecer a história do sujeito, a história de suas relações e a inteligibilidade que direcionou às ocorrências experienciadas psicofisicamente. Será necessário, ainda, compreender como este sujeito se fez e como vem organizando seu movimento no mundo, para que se demarque o que o levou a sentir-se inseguro quanto à realização de seu projeto. Esse é o caminho que tornará possível ultrapassar as inviabilizações experimentadas, para que o projeto deste sujeito seja reorganizado (Schneider, 2011).

A partir, então, da perspectiva de que a psicopatologia é uma perturbação sempre psicofísica que acontece entrelaçada à biografia do sujeito, este estudo teve como objetivo compreender a constituição da psicopatologia por meio da narrativa de uma história de vida, tendo como base a fenomenologia e o existencialismo. Buscou-se, por meio do relato do participante, compreender de que modo foi possível que este sujeito tenha se "complicado psicologicamente" a ponto de experimentar o sofrimento e o adoecimento psíquico, chegando a receber o diagnóstico psiquiátrico de Transtorno Esquizoafetivo.

O Transtorno Esquizoafetivo atualmente está classificado, segundo a CID-10, em transtornos esquizoafetivo tipo maníaco, tipo depressivo, tipo misto, outros transtornos esquizoafetivos e não especificados. Esses transtornos são episódicos, nos quais os sintomas esquizofrênicos e afetivos se destacam dentro de um mesmo episódio de doença. Um diagnóstico de transtorno esquizoafetivo deve ser feito apenas quando ambos os sintomas, esquizofrênicos e afetivos, são proeminentes simultaneamente dentro do mesmo episódio de doença (OMS, 1993). Se- gundo o DSM-5 o diagnóstico baseia-se em uma avaliação de um período ininterrupto da doença no qual o sujeito continua com sintomas ativos (APA, 2014) ${ }^{3}$.

A proposta deste artigo, então, é a de colocar "entre parênteses" este diagnóstico fornecido pela psiquiatria tradicional, rompendo com a ideia de que este sujeito tenha, por ele mesmo e "em nível mental", apresentado um conjunto de sinais e sintomas que o levassem a tornar-se "mentalmente perturbado". Propõe-se então pensar a doença como um fenômeno que se realiza no núcleo da existência do sujeito, a partir da abordagem dos fenômenos psicológicos proposta por Jaspers (1987) de que: a) a psique humana exprime-se no corpo; b) o homem vive em seu mundo; c) o homem objetiva-se na fala, no trabalho e nas ideias.

Para compreender esta lógica fenomenológica existencialista da psicopatologia é necessário compreender as conexões da vida psíquica, devendo ser feita a partir da biografia do sujeito entendida como apresentação formativa de uma unidade individual no todo de uma existência. Assim torna-se necessário compreender o homem todo em sua enfermidade, a doença enquanto uma dimensão da vida do sujeito.

\section{Metodologia}

A pesquisa se constitui como de abordagem qualitativa, visto que buscou compreender os fenômenos humanos como parte da realidade social (Minayo, 2010). Para o alcance dos objetivos foram realizadas entrevistas narrativas por meio das quais, em uma situação de estímulo, o entrevistado contou sobre eventos de sua vida e sobre a trajetória de seu sofrimento (Jovchelovitch \& Bauer, 2015).

O participante foi acessado por meio da rede de relações dos pesquisadores, configurando uma amostra por conveniência (Gil, 2008). Os critérios estabelecidos para a participação no estudo foram: ter recebido diagnóstico de transtorno mental, ter realizado tratamento em instituições ou serviços psiquiátricos e ter seu quadro estabilizado (com ausência total ou parcial de sintomas, que possibilitem um quadro emocional estável).

Assim, pessoas do convívio dos pesquisadores indicaram potenciais participantes para a pesquisa e, mediante o fornecimento de algumas sugestões, a primeira pessoa contatada foi $\mathrm{Lino}^{4}$, um homem de 53 anos diagnosticado com transtorno esquizoafetivo há 24 anos. No primeiro contato, por telefone, foram fornecidas informações básicas acerca do estudo e agendado um contato presencial em local e

\footnotetext{
3 Não se propõe aqui negar a existência de sinais e de sintomas que podem ser verificados e descritos conforme proposto por esses manuais. Trata-se, contudo, de compreender que esta descrição é somente uma parte do processo a ser realizado no cuidado aos sujeitos e que, portanto, o estudo das psicopatologias deve principalmente incluir a dimensão subjetiva da experiência do adoecimento e seus aspectos relacionais, conforme proposto por Serpa Junior et al (2007). 4 Nome fictício.
} 
horário de preferência do sujeito, mas que garantisse o sigilo e privacidade. Na presença de Lino, a pesquisa foi apresentada em detalhes e mediante seu aceite de participação, foi lido e assinado o Termo de Consentimento Livre e Esclarecido. Neste primeiro dia foi realizada a primeira das três entrevistas, ocorridas todas no período de uma semana, totalizando aproximadamente 5 horas de gravação em áudio.

Como técnica de coleta de dados foi realizada a Entrevista Narrativa, permitindo ao pesquisador abordar o mundo experimental do entrevistado, de modo abrangente (Flick, 2009). Esta técnica costuma focar as experiências biográficas, objeto de estudo desta pesquisa. Durante as entrevistas, o pesquisador buscou conhecer a trajetória de relações do sujeito e seu modo de constituir-se enquanto ser no mundo, resgatando sua história de vida, suas experiências, vivências concretas e suas relações familiares e sociais. Também procurou investigar a história do sujeito relacionado à psicopatologia: quando iniciaram os sintomas, como se deu a trajetória da complicação psicológica em relação às vivências concretas; como isso foi vivenciado no contexto em que vivia e quais foram as trajetórias de tratamento.

Conforme destacam Jovchelovitch e Bauer (2015), as entrevistas narrativas buscam reconstruir acontecimentos a partir da perspectiva do informante, abordando aspectos de sua experiência em profundidade. Com a finalidade de organizar a entrevista, foram realizadas questões gerativas, tendo por finalidade estimular a narrativa principal do entrevistado (Flick, 2009). Entre os questionamentos efetuados, estiveram: "Fale-me sobre sua vida". "Descreva sobre suas experiências vividas na família e sociedade geral: na infância, na adolescência, na juventude e na idade adulta". "Conte-me a trajetória de sua psicopatologia: primeiros sintomas, o diagnóstico, tratamentos possíveis e o relacionamento social a partir de então".

As entrevistas foram gravadas e posteriormente transcritas para análise aprofundada do fenômeno estudado. A análise dos dados se deu por meio do método de Análise da Narrativa, buscando a compreensão de como o sofrimento psíquico foi constituindo-se ao longo da história de Lino. O trabalho da análise envolveu a busca dos eixos de significado do material produzido, estabelecendo-se conexões que poderiam constituir respostas à pergunta da pesquisa. A análise caminhou, então, em direção a uma articulação desses eixos em um texto unificado, visando uma síntese (ainda que provisória) do material concreto. Com esse resultado, propôs-se a construção de uma compreensão do fenômeno (Amatuzzi, 2009).

Sobre o processo de análise da narrativa, Jovchelovitch e Bauer (2015) destacam que, inicialmente, é tarefa do pesquisador social escutar as falas dos sujeitos de modo flutuante, em seus detalhes, compreendendo que a narrativa privilegia a realidade do que é experienciado por quem a conta, não estando sujeita à necessidade de comprovação dos fatos, visto que elas expressam a verdade de um ponto de vista. Em seguida, é preciso situar as narrativas dos sujeitos no contexto sócio-histórico em que elas foram produzidas e estão inseridas, sendo então analisadas em relação a este amplo contexto de constituição de experiências e das falas.

Então, por meio da análise de narrativa, buscou-se a reconstrução social da história para a história de vida e da história de vida para o coletivo, propondo-se a uma análise que dê conta do sujeito como social, ou seja, de uma narrativa que possibilite compreender o modo como os fenômenos se constituem em sua interseção entre individual/coletivo, singular/universal. Ou seja, por meio da análise da narrativa, buscou-se compreender de que maneira a forma como o sujeito conta sua história pode oferecer também o acesso a outras dimensões, como à coletiva. Entende-se, assim, que ao contar sua vida, o sujeito fala de seu contexto - fala do processo por ele experimentado, intimamente ligado à conjuntura social onde ele se encontra inserido (Silva, Barros, Nogueira \& Barros, 2007).

A seguir será analisado, então, como o transtorno esquizoafetivo diagnosticado foi se constituindo a partir das relações de Lino com o mundo, tendo como base os pressupostos teóricos da fenomenologia e do existencialismo. Sua história é longa, complexa e cheia de detalhes - assim como toda história de vida humana - e, portanto, ainda que se desejasse, não seria possível esgotá-la. Destaca-se que a análise almejada nesse trabalho é compreensiva, e não analítica, ou seja, justamente pretende-se escapar de uma visão de causalidade, mas sim compreender de que modo o movimento realizado no mundo por este sujeito foi criando condições para que a psicopatologia pudesse ocorrer.

\section{A História de Lino}

Lino é um homem de 53 anos de idade, pós-graduado e ex-professor de uma Universidade da qual foi afastado devido às complicações psicológicas. Filho mais velho de três irmãos, diz ter sido "o desbravador da família”, natural de uma cidade na região sul do país que, na época de seu nascimento, contava com aproximadamente setenta mil habitantes.

Diz ter sido uma criança e um adolescente curioso, com desejo de saber sobre a vida, de conhecer o mundo e as pessoas. Gostava de ouvir música, de ir para a escola e apreciava a arte. Conta de episódios em que buscava se entrelaçar com pessoas, amigos, colegas, importando-se com o bem-estar daqueles com quem convivia. Vivia um contato intenso com a natureza, com animais, circulava pela cidade com propriedade. Buscava, conforme descreve Schneider (2011), experiências de tecimento e trocas afetivas, ou seja, laços de reciprocidade. 
Por meio da família, teve desde o início da vida um contato com igreja luterana. Refere que na religião encontrava espaço de escuta e sensação de pertencimento, pois era compreendido e orientado em suas percepções, desejos e ações no mundo. Sobre isso, afirma:

com 14 anos a gente se confirma ${ }^{5}$, e eu tinha uma sede muito grande pela religião, curiosidade, um pouco dos meus porquês da infância talvez eu aproveitei aproveitando do pastor (...). Eu era muito ativo, muito provocador, gostava muito de saber, de perguntar, e na maioria das vezes eu era atendido, então como eu era atendido e como eu participava, aquilo me incentivava, me deixava assim mais livre, sensação de liberdade, e feliz, acho que quanto tu é livre, tu é feliz.

As experiências na igreja apontam a importância que tinham para ele essas mediações, o desejo de ser ouvido, de ser compreendido e de ter suas experiências organizadas junto aos outros. Encontrava ali as sustentações capazes de oferecer alguma segurança ontológica para o seu ser (Laing, 1982). Era junto dessas pessoas que pôde encontrar, muitas vezes, amparo para superar dúvidas e incertezas em relação a quem era e sobre as escolhas que poderia empreender em função do seu desejo e do seu ser por realizar.

Por outro lado, em família, a religião aparecia mais como um dever a cumprir, na forma de uma moralidade estabelecida, e não enquanto elemento organizador do sentido da vida. Nessa perspectiva, Lino conta de experiências de solidão e isolamento, pois refere tarefas a desempenhar, poucos diálogos, interação escassa com seus pais, que aparecem como pessoas que se preocupavam com os comportamentos, padrões de normalidade e de moral. Portanto, estavam mais preocupados que os filhos fossem exemplos, não fossem motivo de vergonha para sua rede social, do que efetivamente auxiliar os filhos no desenvolvimento de seu ser, de mediá-los em sua relação com o mundo. Assim, os pais batiam, puniam, não brincavam com ele. Portanto, não se teciam, não estabeleciam laços de reciprocidade que fossem capazes de viabilizar as crianças/adolescentes na sua relação com o mundo e com os outros, auxiliando-os a compreender suas possibilidades de ser e de não ser (Schneider, 2011).

Assim, tanto na escola quanto em casa Lino tinha seus amigos e seu irmão mais novo com o quais brincavam, ainda que brincasse muito sozinho. Porém, também relembra de suas "desobediências" para com seus pais e brigas constantes com seu irmão, relembra que apanhava muito deles. Comenta que diante de uma situação, apesar de não relatar como foi a atitude dos pais, aponta que teria sido a pior possível: “Nós apanhávamos né, era comum

5 Refere-se a um evento solene de conclusão do período de Ensino Confirmatório da Igreja Luterana. a mãe bater em nós (...) meu pai também me bateu muito, por muitas vezes me bateu bastante".

Ainda diante da responsabilidade assumida em casa, que considera precoce, e das suas perguntas não respondidas, Lino menciona questões relativas às suas escolhas e liberdade. Não tinha espaço para seus questionamentos e assim percebe que não poderia fazer as escolhas que gostaria, sentia-se cerceado em sua liberdade: "Eu não tive muito a oportunidade de escolher sabe, nessa questão da liberdade da escolha, eu preferia ter feito minha oitava serie de dia junto com meus companheiros”.

Em seu discurso, os pais são citados raras vezes e, quando são, estão em situações de "correção" e de aprendizado de regras sociais, apesar das diversas tentativas de Lino de tecer-se nessas relações. Sua família oferece, portanto, espaço para que se constitua enquanto alguém que "deve ser" determinado sujeito: comportado, religioso, obediente, não dando a ele condições para que avaliasse a realidade e fizesse escolhas em consonância com quem era e que o aproximassem de quem desejava ser. Diante da mediação normativa da familia, começa a experimentar impasses inviabilizadores do seu projeto de ser.

Segundo Schneider (2011) a realidade humana é costurada por laços de reciprocidade, em que cada um é um meio do outro realizar seu projeto. Este é um processo de socialização, de tecimento afetivo existencial com os outros que são significativos para o sujeito. Neste processo, é importante diferenciar o que se configuram enquanto relações sociais, que ocorrem quando o sujeito participa de certos grupos sociais relacionando-se com diversas pessoas, de relações sociológicas, que são relações de mediação que definem o espaço do sujeito para muito além do social, numa dimensão de mútuas implicações de ser, que são definidoras do seu projeto. Neste último modo de relação está implicado o grupo familiar, que tem o papel fundamental na mediação do projeto de ser do sujeito entre ele e a sociedade.

Nesta rede de tecimentos, haverá mediações consideradas positivas, que viabilizam o projeto de ser do sujeito e o incentivam a ser quem ele deseja ser, e há mediações negativas, que inviabilizam o desejo de ser, levando-o a experimentar-se "determinado" a ser "certo” sujeito (Schneider, 2011). Nos relatos de Lino, observa-se que este fazia parte de um contexto familiar - cúmplice talvez de um contexto social e cultural de sua época - mediado, por assim dizer, negativamente, e que foi decisivo para que vivenciasse situações de insegurança de ser, impasses psicológicos e experiências de solidão (Laing, 1982; Schneider, 2011).

Era filho de uma família que tinha um padrão de vida estável financeiramente, mas também permeado de contradições, visto que, se por um lado a família se esforçava sem "ser exemplo para a sociedade” e usufruía de certos privilégios econômicos, 
por outro, seus membros vivenciavam conflitos intensos, o que levou Lino a descrever seu início de vida como "um tanto quanto perturbado". Nas suas palavras: "Quando eu, depois nasci, a gente foi morar com o padrasto da minha mãe, a minha avó, a mãe da minha mãe, e ele bebia muito, foi um período muito ruim, sabe, bastante irônico".

Desde muito cedo lhe foram atribuídas atividades domésticas que Lino define como "responsabilidades precoces". Ao cuidar de sua irmã mais nova, aos seis anos de idade, fala de uma paternidade aprendida e imposta em um momento de sua vida em que, acreditava, deveria ter brincado mais. Fala sobre esta fase da vida como uma "fase dos porquês", em que suas curiosidades não foram sanadas devido às responsabilidades que deveria dar conta.

Eu praticamente tinha que cuidar da minha irmã, então era criança cuidando de criança, não era certo né (...) uma coisa que me marcou bastante isso assim essa experiência com ela, uma paternidade imposta, né, uma responsabilidade de cuidado né, muito precoce, quando criança queria mais brincar né.

Conforme já descrito anteriormente, nesta família, Lino é apresentado a princípios religiosos bastante rígidos. Além disso, dentro da moral familiar, deveria obedecer a seus pais, cuidar de seus irmãos, ir à igreja. Tudo que pudesse escapar da obediência era considerado, então, pecado, quando Lino experimentava o medo de não ser bom e de não ser o filho que desejava ser para seus pais. Por outro lado, vivia em intenso contato com a natureza, com a liberdade e inocência, em que gostava de estar com outras pessoas, tocar seu corpo, experimentar as sensações que este corpo possibilitava.

Foi assim que, por volta dos seis anos de idade, experimenta "excitações sexuais", assim denominadas por ele, tanto homossexuais como heterossexuais, com meninas de sua idade e com outro homem de sua parentela de maior idade. Do modo como ele as conta, observa-se que inicialmente não faz uma reflexão crítica acerca destas vivências, apenas as experimenta na espontaneidade da infância: "a gente fazia umas brincadeiras assim, brincar de médico [...] a gente brincava ali naquele terreno, sem penetração, só excitação mesmo, bem precoce, bem novo e quase que empiricamente, não foi assim induzido nada, tudo empírico".

Já um pouco mais velho, Lino vivencia a contradição entre as sensações que o corpo oferece com antecipações de que estas tinham algo de errado, ou seja, com o passar dos anos e a capacidade reflexiva desenvolvida, essas vivências foram compreendidas por ele como erradas, próximas ao pecado e, portanto, ameaçadoras do seu desejo de "ser bom e ser correto". É assim que, então, procura sua mãe e busca contar-lhe sobre uma das vezes em que experimen- tou-se "assediado" por um homem mais velho. Em sua memória de adulto, refere não ter certeza de ter sido ouvido ou considerado por sua mãe. Isso o intriga, pois refere memória de ter contado a ela, mas não tendo memória sobre o que ela teria dito em resposta, se questiona do porque ela não ter feito nada para evitar tal situação. Atribui à mãe certo grau de culpa por não ter agido ou ter ouvido/creditado aquilo que lhe falava ou precisava falar.

Isso tudo assim foi uma situação bastante diferente pra mim, nova, eu não tava maduro pra isso, criança não tá madura prá isso (...) e eu contei prá minha mãe (...) me causa intriga porque, pra mim eu falei e eu não sei se eu falei ou se eu não falei, não importa se eu falei ou não falei, agora se eu falei e ela não fez nada, ela se omitiu, e quem se omite aprova, então ela, ela não teve estrutura pra, pra reagir.

Observa-se no relato de Lino que as vivências relacionadas à sua sexualidade ocupavam parte importante de sua infância. Porém, devido à sua condição infantil, precisavam do auxílio dos adultos para serem organizadas e apropriadas por ele de modo viabilizador de seu ser. No entanto, não lembra de ter se sentido amparado pela mãe, nem de ter obtido dela auxílio na elaboração destas experiências, o que o levou a experimentar insegurança em relação ao seu modo de se colocar naquela ação e sobre as implicações que a mesma poderia ter na sua vida.

Hoje Lino considerara-se uma pessoa desconfiada e atribui essa desconfiança àquelas experiências sexuais. Acredita que todos os homens que se aproximam dele têm interesses sexuais precisando sempre ficar atento para situação: "minha desconfiança está ameaçada aí, porque todo cara que age de uma forma assim (...) pode ser por interesse sexual, então eu sempre tenho que fica com um pé atrás".

Para Cooper (1989, p. 56) as famílias mediam a realidade social para seus filhos. Uma vez que essa realidade social estiver cheia de formas alienantes "que dizem respeito ao ato de negação da ação num grupo e aos resultados desta ação" - essa alienação será mediada ao filho de forma individual sendo experimentada como um estranhamento nas relações da família. Entende-se aqui estranhamento como um sentimento de ser agarrado num processo que se torna distante das próprias intenções e atos da pessoa e de cada outro membro do grupo. As famílias com membros esquizofrênicos exibem uma espécie de alienação e estranhamento particularmente intenso. Nesse contexto esse membro do grupo identificado como esquizofrênico está tentando se livrar desse sistema alienado por meio de seus episódios psicóticos. Nessa realidade social, o sujeito interiorizou uma restrição peculiar do seu campo de possibilidades, no qual as respostas psicóticas podem ser as mais razoáveis possíveis até que o campo social seja alterado. 
Assim, as atitudes de Lino foram tomadas como "estranhas" ao grupo familiar em sua infância e adolescência, sendo coibidas, uma vez que "ameaçavam" a imagem da família religiosa e de moral irretocável. Em várias ocasiões Lino vivenciou, assim, duas forças sociológicas ${ }^{6}$ antagônicas se impondo: de um lado, suas experimentações psicofísicas, relacionadas a uma vivência prazerosa no contato com outros, a uma vida de curiosidade e, de outro, uma moral religiosa dura, que não tornou possível o diálogo com os adultos significativos e a organização destas vivências em relação ao seu ser, deixando-o inseguro quanto a elas e impelindo-o a certa solidão na elaboração sobre quem era/é.

Sobre este aspecto, ressalta-se que o sujeito nasce com uma condição fisiológica, condição de possibilidade de seu ser se estabelecer. Portanto, o homem se constitui mediado pelo sociológico. A estrutura social na qual o sujeito está fornecerá parâmetros para construir sua singularidade. As pessoas que o cercam, desde cedo vão traçando para ela um projeto ao efetivarem expectativas em seu contorno e o processo das primeiras relações é definidor da construção da personalidade do sujeito. O relacionamento cotidiano com os outros vai possibilitando ao sujeito constituir seu ser (Schneider, 2011).

Na infância, o processo de construção do ser é experimentado pelo sujeito como uma forma de alienação, pois uma criança não nasce com a capacidade de refletir, apenas estabelece relações espontâneas com o ambiente, não tem condições lógicas nem psicológicas de ter autonomia. Vive neste momento seu ser como um "ter-que-ser", o eu enquanto uma tarefa a realizar. Somente mais tarde, com o processo de relação com o mundo, mediado por outras pessoas, é que aprenderá refletir e abstrair. Aos poucos as relações vão se expandindo para além do ambiente familiar ou institucional dialetizando os valores e a inteligibilidade social, contribuindo para realizar reflexões críticas e relativizar os processos de mediações estabelecidos até então, para enfim, tomar o seu ser em suas mãos. Aqui ocorre o chamado "nascimento existencial", quando a criança rompe "a placenta social" e nasce para o mundo autônomo, superando o dever-ser para o poder-ser, não vivendo mais seu ser como tarefa, mas como um conjunto de possibilidades (Schneider, 2011).

Muitas vezes as pessoas não conseguem nascer existencialmente, ficando presas nessa placenta social familiar ou institucional. Vários são os fatores que levam a esta situação, entre eles a concepção lógica formal que sustenta nossa sociedade, que inviabiliza as pessoas de compreenderem a si mesmas, em termos de possibilidade, de vir-a-ser. Acabam vivendo dentro do determinismo do dever-ser, sendo

\footnotetext{
6 Forças enquanto "ação que se realiza à distância", ou seja, como ação virtual (Sartre, 1939/2006). Segundo Schneider (2006, p. 291) "forças sociológicas, as que nos interessam na questão da dinâmica psicológica, são ocorrências de pressão social, advindas de seu contexto material, sociológico, que levam o sujeito a experimentar-se atraído ou repelido por certas situações".
}

esses ambientes (familiares ou institucionais) comumente produtores de loucura (Schneider, 2011).

Neste sentido, a loucura pode ser compreendida enquanto uma experiência de ser e do mundo que rompe com o aquilo que, em determinado grupo familiar e social, seria permitido experienciar, sendo então a psicopatologia uma questão de um vivido que não é compreensível para os outros (Laing, 1982). Na medida, então, que aquilo que vive não pode ser organizado junto à rede sociológica, o sujeito inicia um processo de divisão do ser: como forma de se proteger das eventuais ameaças externas, o ser divide-se num self subjetivo e em um self do corpo, sendo este último um self falso que procura de alguma forma corresponder às expectativas que os outros têm sobre si. Como resultados deste consentimento dos desígnios dos outros pelo sistema de falso self ocorre, por um lado, um aumento na intensidade do medo de agir de acordo consigo mesmo e, por outro, um ódio que se instalaria, uma vez que a pessoa se sente cada vez mais em perigo de invasão por alguém (Laing, 1982).

Assim, ao longo da trajetória de Lino, vai se formando uma divisão colocada em seu movimento no mundo, em que forças sociológicas opostas vão se impondo: por um lado, sente-se exigido a ser o filho responsável, mais velho, que ajuda a família e que cumpre com o que lhe é solicitado (ser religioso, obediente); por outro, deseja ser este que se experimenta em liberdade, que quer conhecer, experimentar o mundo e dividir com outros suas experiências. Esta é a chave para a compreensão de como a psicopatologia pôde se estabelecer no núcleo da existência de Lino, tendo em vista a impossibilidade de viabilizar em um projeto estas duas forças antagônicas e, portanto, inconciliáveis: se for um, não poderá ser outro.

Neste sentido, descreve Cooper (1989) que na família da pessoa destinada à designação de esquizofrênico, as leis do grupo familiar, que regulam não apenas o comportamento, mas também o que pode ou não ser vivido, são, ao mesmo tempo, confusas e inflexíveis. Nela, ensinam à criança que, se violar as regras do grupo, este ato causará a dissolução da família e a destruição de seus membros individualmente. Desta maneira, a criança é progressivamente colocada numa posição insustentável, tendo em vista que sua escolha, no ponto crítico final, é somente uma escolha entre

de um lado, a submissão total, o abandono total de sua liberdade, e de outro lado, a saída do grupo, o qual impõe a angústia de testemunhar a devastação profetizada pelos outros e a luta com a culpa que, com cuidado tão afetuoso, foi implantada na criança. A maioria dos esquizofrênicos predestinados encontra uma resposta sintética para este dilema, que em geral coincide, no atual estado de coisas, com a resposta 
encontrada para eles por suas famílias, ou seja, sair da família, mas sair dela para entrar no hospital psiquiátrico (Cooper, 1989, p. 37-38).

Neste contexto sociológico, o futuro de Lino estava sendo traçado com precisão e rigidez por sua família, visto que, a fim de se ajustar às experiências passadas e às necessidades de seus membros, deixavam-lhe pouco espaço para ser algo ou alguém por sua própria iniciativa. Assim, "seu ser-para-os-outros (ser objeto) tinha para ele precedência ontológica sobre seu ser-para-si (ser sujeito)” (Cooper, 1989, p. 77).

Quando questionado sobre sua vida para além da família e para além da infância, Lino começa falando sobre seus primeiros trabalhos. Relata que começou a trabalhar ainda na sua adolescência, aos 16 anos de idade. Em uma das primeiras empresas que trabalhara, ainda na sua juventude, a empresa tinha uma gestão que considerava rígida, sendo o ambiente de trabalho "constrangedor". Descreve Lino que

O clima na [empresa] me constrangia, você era assim... vigiado, existia um controle. Eles eram muito curiosos, muito interessados nas coisas pessoais [...], eles queriam ter esse poder, não só no profissional como no pessoal sabe, nazista, nazista, sentimento nazista, o homem era fogo [referindo-se ao dono da empresa].

As experiências que teve nestas relações demonstram como novamente não experimenta reciprocidade e pertencimento nos ambientes para além da família. Justamente por ser este sujeito que busca o tecimento em suas relações, busca fazer-se com os outros, as situações em que esta experimentação lhe é negada tem força constitutiva no seu ser. Lino era esse sujeito preocupado em compartilhar aquilo que conhecia com outras pessoas, mas por diversas vezes sentia que o valor que dava às situações não era o mesmo que as outras pessoas davam. Experimentava-se, assim, em solidão, visto que grande parte das vezes em que tentou compartilhar e ser com os outros, em reciprocidade, isso não foi possível. Sendo assim, experimenta fracasso em suas tentativas de estabelecer tecimento em suas relações, experimentando inviabilizações de seu projeto de ser. Tornando-se cada vez mais inseguro sobre quem era, impelindo-o cada vez mais ao isolamento.

Deste modo, é importante considerar que o sujeito age no mundo e depois se apropria do que fez à luz da mediação dos outros, sendo suas ações inteligíveis somente no/a partir de sua situação (Sartre, 1943/1997). Desse modo, os comportamentos considerados doentios devem ser compreendidos a partir das relações com os outros, visto que, inclusive, alguns comportamentos podem ser considerados "normais" ou "patológicos" de acordo com os diferentes contextos em que ocorram.
Até esta parte da narrativa de Lino, foi possível estabelecer a compreensão das condições de possibilidade para que seu adoecimento tenha ocorrido ao longo de sua constituição como sujeito, visto que se elucida como o impasse e a tensão entre forças contraditórias sobre o seu ser foram se estabelecendo e a dificuldade que encontra para viabilizar seu projeto em meio a este conjunto de determinantes sócio históricos. Há, assim, um contexto antropológico de gênese, que produz um campo de forças sociológicas que estão na do seu processo de personalização e, consequentemente, de complicação psicológica (Schneider, 2006).

A partir deste ponto da narrativa, Lino passa a descrever o conjunto de ocorrências nas semanas anteriores ao que denomina sua primeira crise e que, do ponto de vista teórico, podem ser compreendidos enquanto a formação de uma atmosfera que precipita o rompimento com a realidade, por volta dos seus 30 anos de idade. Neste sentido, deve-se compreender que as coisas que acontecem afetam Lino a partir do modo como ele se experimenta no mundo e de como se apropria daquilo que lhe acontece. Além disso, estes acontecimentos são vividos na espontaneidade, ou seja, na alienação, sem que ele possa se tomar como objeto de reflexão, ficando aprisionado em um impasse, enquanto uma contradição não dialetizável, e de uma experimentação cúmplice de situações vivenciadas no passado (Castro, 2012).

Assim, Lino conta que na época precedente à sua crise, sua irmã se envolvera em um relacionamento extraconjugal, no qual a mulher do suposto homem com quem se envolve procura sua mãe a fim de tirar satisfações. Porém, sua irmã não estava em casa e sua mãe ouvira o que a mulher teria a dizer ficando muito magoada com a atitude da filha, pois jamais concordaria com a hipótese de a filha destruir o relacionamento de outra família. Quando sua irmã retorna para casa a mãe, em momento de fúria, a chama para conversar e Lino ouve o discurso da mãe, ficando extremamente chocado com a situação, principalmente pelo fato de não poder naquele momento "fazer nada para defender sua irmã", pois a mãe chamara para uma conversa a sós.

A sensação de impotência, visto que se sentiu impossibilitado de proteger a irmã, de quem desde pequeno cuidou, pois esta era uma de suas responsabilidades, faz Lino sentir-se inviabilizado em quem deseja ser:

Minha mão me pediu assim, agora quando a tua irmã chegar tu me deixa com ela, e eu fui pro meu quarto (...) e quando minha irmã chegou ela ouviu tanto, tanto, o que essa mulher falou, não dá pra dizer que era minha mãe. E eu, eu ouvi tudo, sempre cuidei da minha irmã desde pequena, me machucou muito, queria ter ficado junto (...) e eu me magoei com isso, e eu acho que foi ali um dos meus gatilhos. 
Lino retoma, neste momento, a história familiar: sua avó teve sua mãe enquanto solteira, a sua mãe teve ele enquanto solteira, ou seja, tiveram seus filhos ainda antes de oficializar o casamento, sendo que considera tal situação como algo grave diante daquilo que avaliava como certo perante sua conduta religiosa. Lino fica, então, preso entre o que seria "o correto" - e a razão que a mãe teria para punir sua irmã - e o desejo de cuidar e protegê-la, estabelecendo uma relação de mediação mais viabilizadora também para o ser da irmã.

Além disso, também Lino naquela mesma época acaba se relacionando sexualmente com sua namorada - e atual esposa - ainda antes do casamento, levando-o a experimentar um sentimento de contradição, de pecado e culpa em relação àquilo que aprendera. Tendo em vista a moral religiosa da família, relaciona tais fatos com seu sofrimento, indicando um impasse entre viver o que seria de seu desejo e seguir o que estaria determinado a ser: "acabei me relacionando fora do casamento formal, como é que não vai sofrer”.

Estas dúvidas e angústias referentes ao aspecto amoroso de sua vida geraram o que Lino chamou de “incompatibilidades no namoro". Inseguro quanto à sua atitude em relação às experiências sexuais, sentia certa ameaça de que o relacionamento com a namorada poderia não dar certo. Além disso, sentia-se pressionado pelo trabalho que realizava na época, como professor de economia, questionando-se se daria conta das exigências que lhe eram feitas, apontando para um ser que está em questão e para situações de impasses, ameaçadoras do futuro desejado por ele.

Estando em período de férias, Lino tinha uma série de trabalhos e provas para corrigir. Estas experiências somavam-se aos acontecimentos na vida pessoal, deixando-o tenso: "Eu estava bastante agitado, contrariado, nervoso (...) estava em férias escolar, parei de lecionar, estava com trabalhos para corrigir. Estava passando por um problema no namoro, estava meio inseguro".

Em seguida, Lino conta que, também neste período de férias, assistiu a uma peça de teatro na cidade a qual também considera como "um dos gatilhos para suas crises". Uma peça que de certa forma falava sobre o mundo sobrenatural e acabou tocando nas questões relacionadas às suas escolhas e liberdade. Uma peça de teatro que uma empresa de escovas dentais patrocina e estava sendo apresentada nas escolas em forma de marionetes, em que o dente, o anjo e o diabo conversavam. O diabo estava instigando o dente a não fazer nada que lhe proporcionasse limpeza, e tinha um anjo que, ao contrário, colocava ideias que os dentes deveriam ser limpos para evitar problemas futuros.

Dessa história do bem e do mal, do diabo e do anjo, me tocou muito, bateu forte mesmo a questão, depende passou bem pra parte prática da vida, sabe, é bem assim a parte do livre arbítrio, é livre sua escolha se você quer tratar os dentes ou não.
No dia seguinte Lino fica sabendo que a mesma peça seria apresentada em outra escola. Almejava muito levar seu irmão para assistir, mas não consegue, levando consigo uma colega sua. Mais tarde, fica sabendo que no dia seguinte a encenação aconteceria em outra escola, e gostaria muito que sua mãe fosse com ele. A mãe aceita, mas junto com Lino não consegue chegar ao local em tempo para assistir ao teatro, pois no caminho encontram uma mulher caída na rua e páram para prestar ajuda, fazendo com que se atrasem. Nesta ocasião, Lino conta que já estava bem agitado, alterado, mas, apesar de se considerar uma pessoa um tanto quanto quieta, seus pais não perceberam nada.

Sente-se, portanto, angustiado por não ter compartilhado com seu irmão e sua mãe algo que lhe era tão importante. Observa-se o desejo de ser com os outros, de possibilitar à mãe e ao irmão a vivência de algo que lhe havia tocado profundamente, que lhe fazia pensar sobre o mundo, sobre a vida e sobre si. Porém, não consegue fazê-lo e, não sendo possível essa relação de reciprocidade, se angustia, agitando-se psicofisicamente.

Nestas mesmas semanas, em que vivenciava a dificuldade para apoiar a irmã, os problemas no namoro, a pressão no trabalho e a impossibilidade de levar sua mãe e seu irmão à peça de teatro, Lino estava lendo o livro do Pedro Bandeira que se chama "Agora Estou Sozinha...”. Conta que o livro narra a história de uma mulher que acabara de perder sua mãe e que precisaria enfrentar o fato de seu pai se casar dois meses após sua viuvez. No enredo, sua mãe lhe aparece em sonho dizendo que havia sido assassinada e pede vingança. A personagem vive, assim, momentos conflitantes sem poder falar da situação a ninguém. Neste sentido, o livro retratava o impasse da personagem que era também um retrato dos impasses vivenciados por Lino, visto que ele vivia momentos difíceis, sentindo-se sozinho e sem poder compartilhar com outros suas dúvidas, não obtendo auxílio para viabilizar seu ser.

Já afetado por todos estes acontecimentos, Lino, diante de suas habilidades manuais, se propõe a desenvolver produtos artesanais com um de seus amigos. Esta era uma nova tentativa de ser com os outros, de tece-ser, tanto na sociedade estabelecida com seu amigo, como no momento e que ofertava seus produtos às pessoas. Por meio das vendas, buscava interagir com as pessoas, mostrando a elas aquilo que considerava bom e importante - mostrava suas habilidades e potencialidades. Porém, depois de algumas tentativas, fala que as pessoas pouco se importavam ou davam valor àquilo que fazia e, acabando por vivenciar o fracasso financeiro, a sociedade se dissolveu.

Neste mesmo período conta outro fato que hoje considera um absurdo, mas que naquele momento para ele fazia sentido, demonstrando o quanto as ocorrências anteriores já o estavam afetando em sua 
relação com o mundo, dificultando posicionar-se de modo crítico. Junto com sua namorada, numa tarde saíram para visitar um casal de amigos. Após a visita, Lino pede ao casal para levar duas de suas filhas, não sendo atendido em sua solicitação. Fala que queria apenas levá-las para morar com eles - provavelmente em nova tentativa de compor uma rede, talvez uma família. Hoje considera absurdo o que estava pedindo, mas naquele momento tenso e agitado antes da sua primeira crise, "tudo fazia sentido".

Por fim, um último episódio contribui para a ocorrência do "surto" de Lino. Era o ano de 1992 e durante um jogo no Estádio do Maracanã, uma grade do anel superior caiu, vitimando fatalmente três pessoas nesse acidente. Estava na casa de um colega seu, alterado, momentos antes da sua primeira crise, e assistindo o jogo fica chocado quando o acidente ocorre: "Aquilo me chocou tanto aquele acidente (...) eu achei que era um absurdo pessoas irem pra um lugar e voltarem sem vida pra casa né, quer dizer, pro cemitério. Eles esperavam uma tarde agradável".

Ao sair da casa de seu colega, Lino encontra seu cunhado, sua namorada e sua mãe, que o convidam para irem para casa. Estava extremamente alterado, pois, após todos os acontecimentos narrados até aqui - o estresse no trabalho, a incerteza no namoro, a peça de teatro que sua mãe e seu irmão não conseguiram assistir, a sociedade feita e desfeita, a proposta de levar para sua casa as crianças do casal que visitaram e a morte de pessoas no acidente do Maracanã -, vivia a angústia e a dificuldade de organizar o modo como estes eventos o tocaram. Além disso, em todas essas situações, descreve que, ao buscar sentido por meio dos outros, estava sozinho: ninguém de sua família ou amigos se comoveu com a morte no acidente no estádio, a namorada não compreendeu seu desejo de levar as crianças para morarem com eles, a mãe e o irmão não compreendiam porque a peça de teatro era tão importante e o que tinha de tão especial, pois não puderam ver, mas não lamentavam por isso.

Assim, voltando para casa após saber do acidente do Maracanã, Lino propõe aos membros de sua família rezar em círculo colocando um cachorro preto no meio, talvez em uma tentativa de organizar todas estas experiências e ser compreendido em suas angústias. Porém, é contrariado por seu cunhado, que diz que Lino estaria "ficando louco", e então decide deitar em seu quarto. Ou seja, novamente não encontra amparo, não é compreendido e não se pode tecer com os outros, sendo sua alternativa o isolamento.

Pouco tempo depois que deitara, Lino diz que "percebe algo muito estranho com ele": "repentinamente", estava fora de si, totalmente alterado, dirigindo aos seus pais palavras agressivas sobre sexualidade. Em seguida, entra no banheiro e agressivamente começa a quebrar todas as coisas. Seu relato demonstra que esta alteração é percebida por ele de modo desconectado com os eventos anteriores, que o haviam afetado emocionalmente, dificultando a compreensão de que seu sofrimento ocorre por vivenciar seu projeto de ser inviabilizado.

Deste modo, o confronto com a impossibilidade de viabilizar seu ser na condição sociológica em que se encontrava, em meio a outros que não compreendiam as intenções de suas ações, levou-o ao que denominou de "surto", sendo este o momento de rompimento com a realidade enquanto tentativa de saída da situação vivida como insuportável. Neste sentido, seu surto "é a livre transformação do projeto desejado, que ao ser alienado pela situação, rompe com o real insuportável, irrealizando-o" (Castro, 2012, p. 146), ou, ainda, na medida em que não pode alterar o real, Lino opera uma ruptura com a sua situação, negando-a e, ao mesmo tempo, ultrapassando-a em direção à vida imaginária (Sartre, 1940/1996).

Segundo Sartre (1940/1996), a imaginação é uma das formas possíveis de a consciência se dar, sendo uma das ferramentas psicológicas utilizadas pelos sujeitos para a construção de suas singularidades, visto que possibilita a superação da situação em que está inserido em direção a algo novo, transcendendo sua facticidade em direção ao futuro e, ainda, voltar-se para situações passadas, para suas recordações. Contudo, é possível que um sujeito se complique pelo imaginário, quando não se faz mais mediar pela realidade, mas pelo imaginário na constituição de uma racionalidade a respeito do seu movimento no mundo. Ou seja, o aspecto saudável da imaginação trazido pela condição de ultrapassamento do que está dado, tem seu reverso, seu lado patológico, quando o sujeito ao invés de usar sua capacidade imaginativa para transcender, fica prisioneiro dela (Schneider, 2011).

Assim, a imaginação é uma maneira espontânea de apreender o mundo, em que, diante de situações insuportáveis, o sujeito muda sua relação com o mundo, para que o mundo mude suas qualidades. Portanto, os processos imaginários têm funções e significados que são específicos de cada personalidade e que cumprem papel relacionado sempre à dinâmica de ser do sujeito. Trata-se de uma fuga não só do conteúdo do real (relações tumultuadas, fracassos, humilhações, pobreza), mas também da própria forma como o real se apresenta, das exigências que impõe. O real é sempre novo e imprevisível, está sempre a exigir posturas, atitudes, a produzir emoções. Já o mundo imaginário é de uma "pobreza essencial", só tem aquilo que o sujeito nele constitui (Schneider, 2011, Sartre, 1940/1996).

Na experiência de "crise", Lino vive seu ser inviabilizado e a entrada no imaginário aparece então como uma tentativa de solução dos impasses experienciados, constituindo-se em uma "experiência totalizande de um projeto inviabilizado no plano do real e que se irrealiza como vida imaginária" (Castro, 2012, p. 146). Frente à sua agitação e agressividade 
e de seu discurso desorganizado, não inteligível às pessoas de sua família, seus pais, não sabendo mais como lidar com a situação, solicitam apoio da Polícia Militar para contê-lo. Os policiais o colocam então amarrado sobre uma maca na sala de sua casa. Sobre esse acontecimento, Lino diz que "somente quem passar por algo parecido saberá falar o que ele sentiu". Fala sobre uma pessoa que andara por cima dele, sentia forte cheiro de enxofre, fica preocupado e com medo pensando que alguém dos próprios soldados que ali estavam poderiam lhe fazer algum mal ou até mesmo alguma espécie de exorcismo, reforçando o caráter psicofísico sobre o modo como o mundo o afetava naquele momento:

Não é de hoje que as religiões rotulam o psicótico como um encapetado... a pupila fica tão alerta, os sentidos ficam tão alerta, até o olfato outro sintoma, outro sentido que é o gosto parece que até sente gosto de outras coisas, cheira coisas, coisas de outro mundo, só quem passou por uma coisa assim.. indiscutível... indiscutível.

Sobre este aspecto, Van Den Berg (1981) cita que o esquizofrênico percebe as coisas como uma revolução que se aproxima. Até no gosto do seu pão percebe o mal penetrar nas coisas do mundo, por todos os lados observa poderes satânicos. Ele enxerga, ouve e cheira indícios de desastres nos quais observa, percebe a queda da sua própria existência. Isso significa que não apenas o sujeito está doente, mas que o seu mundo está doente, que os seus objetos estão doentes. O seu corpo se movimenta dentro de um mundo estranho e inseguro. O processo de complicação pelo imaginário envolve, portanto, uma unidade sintética representada pelo sujeito e pelo objeto, ocorrendo sempre neste horizonte de compreensão mágico em que, diante de um mundo que se impõe como ameaçador, o sujeito se utiliza de explicações mágicas para interpretá-lo e justificar sua anulação (Sartre, 1940/1996).

Depois desta primeira crise, Lino foi encaminhado a um hospital geral pela Polícia Militar e após, passar por avaliação médica, é encaminhado a um hospital de referência. Chegando lá, ao acordar no outro dia pela manhã e passar por avaliação médica, solicita ao médico se poderia se apresentar com seu nome original e a partir da enfermidade de "crise de simbologia", nomenclatura com a qual Lino se refere à sua enfermidade até os dias de hoje. No hospital começa construir, então, sua identidade de doente. Para ele, uma pessoa com transtorno mental deixa sua identidade "normal" e passa ter uma identidade de doente, pois as coisas nunca mais serão as mesmas. A partir de então passa a construir sua trajetória de passagem por serviços de saúde mental, sendo diagnosticado com transtorno esquizoafetivo.
Atualmente Lino está afastado de suas atividades de trabalho recebendo tratamentos farmacológicos. Em seu discurso, apesar das referências a uma longa trajetória por diversos serviços da rede de atenção em saúde, deixa evidente que em nenhum deles encontrou a viabilização para o seu projeto de ser.

\section{Considerações Finais}

Esse trabalho teve como proposta principal compreender a constituição da psicopatologia de Lino tendo como base sua história de vida. Buscou-se aqui compreender, a partir de obras da fenomenologia e do existencialismo - entre elas "O Ser e o Nada”, "Questão de método”, “o Imáginário” e "Esboço de uma teoria das Emoções" de J-P Sartre; e textos de Daniela R. Schnheider e de Robert Laing e David Cooper -, como este sujeito foi se complicando psicologicamente até ser diagnosticado com transtorno esquizoafetivo.

Compreender a psicopatologia nesta perspectiva crítica exige ir além daquilo que é dado enquanto critério sintomático, que somente possibilita enquadrar o sujeito num possível diagnóstico. Tal método implica pensar o humano nas relações estabelecidas com o mundo e com os outros. A complexidade dessa tarefa envolve colocar em suspensão a lógica dos critérios diagnósticos para uma busca sobre a compreensão do adoecimento psicológico a partir e por dentro da história do sujeito.

Cada sujeito possui sua história e dentro dela estão as formas como se relacionou e se relaciona com o mundo. O trabalho de análise de uma história de vida é minucioso e, em termos de pesquisa, é também de certo modo provisório. Por se tratar de uma pesquisa de base fenomenológica, a intenção foi captar a experiência do participante a partir de sua descrição, independentemente dos juízos de realidade, ou seja, colocando "em suspenso" conceitos estabelecidos a priori e possibilitando que os sentidos emergissem dos próprios fenômenos.

Finalizado o trabalho, considera-se que tenha sido possível elucidar as condições de possibilidade para que a psicopatologia de Lino tenha se constituído, atrelada à constituição de sua personalidade. A compreensão aqui proposta tem, como fim último, questionar a lógica psiquiátrica hegemônica que, se por um lado deposita no sujeito a responsabilização pelo seu adoecimento, por outro ignora os aspectos da dimensão subjetiva desta experiência, entendendo que, na medida em que outra possibilidade de compreensão acerca do sofrimento estiver disponível, poderão ser ampliadas sua possibilidade de viabilizar-se em seu movimento no mundo e de realizar seu projeto à sua maneira - mas na presença de outros. 


\section{Referências}

Amatuzzi, M. M. (2009). Psicologia fenomenológica: uma aproximação teórica humanista. Estudos de Psicologia (Campinas), 26(1), 93-100.

American Psychiatric Association (APA) (2014). DSM-V, Manual Diagnóstico e Estatístico de Transtornos Mentais ( $4^{\mathrm{a}}$ ed. Revisada). Porto Alegre: Artes Médicas.

Beauvoir, S. (1960). La Force de l'âge (I e II). Paris: Gallimard.

Castro, F. G. de. (2012). Estudos de psicanálise existencial. Vol. 1. Curitiba, PR: CRV.

Charlesworth, M. (1980). Sartre, Laing \& Freud. Review of Existential Psychology \& Psychiatry. Vol.XVII, $\mathrm{N}^{\circ} 1$.

Cooper, D. (1989). Psiquiatria e Antipsiquiatria. São Paulo: Perspectiva.

Flick, U. (2009). Introdução à pesquisa qualitativa $\left(3^{\mathrm{a}}\right.$ ed). Porto Alegre: Artmed.

Gil, A. C. (2008). Métodos e técnicas de pesquisa social ( $\left.6^{\mathrm{a}} \mathrm{ed}\right)$. São Paulo: Atlas.

Jaspers, K. (1987). Psicopatologia Geral: psicologia compreensiva, explicativa e fenomenologia $\left(2^{\mathrm{a}}\right.$ ed). Rio de Janeiro - São Paulo: Atheneu. Vol. 1.

Jaspers, K. (1987). Psicopatologia Geral: psicologia compreensiva, explicativa e fenomenologia $\left(2^{\mathrm{a}}\right.$ ed). Rio de Janeiro - São Paulo: Atheneu. Vol. 2.

Jovchelovitch, S. \& Bauer, M. W. (2015). Entrevista narrativa. In Bauer, M. W \& Gaskell, G. (org.). Pesquisa qualitativa com texto, imagem e som: um manual prático $\left(13^{\mathrm{a}} \mathrm{ed}\right)$. Petrópolis, RJ: Vozes. (PP. 90-113).

Laing, R. D. (1982). O eu dividido: estudo existencial da sanidade e da loucura ( $5^{\mathrm{a}}$ ed). Petrópolis: Vozes.

Laing, R., \& Cooper, D. (1982). Razão e Violência: uma década da filosofia de Sartre (19501960). Petrópolis: Vozes.

Minayo, M. C. S. (2010). O desafio do conhecimento: Pesquisa Qualitativa em Saúde $\left(12^{\mathrm{a}} \mathrm{ed}\right)$. São Paulo: Hucitec-Abrasco.

Organização Mundial da Saúde (OMS) (1993). Classificação de Transtornos Mentais e de Comportamento da CID-10: Descrições Clínicas e Diretrizes Diagnósticas. Porto Alegre: Artes Médicas.
Serpa Junior, O. D. de, Leal, E. M., Louzada, R. de C. R., \& Silva Filho, J. F. da. (2007). A inclusão da subjetividade no ensino da Psicopatologia. Interface - Comunicação, Saúde, Educação, 11(22), 207-222.

Sadock, B. J. \& Sadock, V. A. (2011). Manual conciso de psiquiatria da infância e adolescência. Porto Alegre: Artmed.

Sartre, J-P. (1978). Questão de método. Coleção Os Pensadores. São Paulo: Abril Cultural. (Original publicado em 1945).

Sartre, J-P (1996). O imaginário. (D. Machado, Trad.) São Paulo: Editora Ática. (Original publicado em 1940).

Sartre, J-P (1997). O ser e o nada (12 a ed). Petrópolis: Vozes. (Original publicado em 1943).

Sartre, J.-P. (2006). Esboço para uma teoria das emoções. Porto Alegre: L\&PM (Original publicado em 1939).

Sartre, J.-P. (2015). O Idiota da Família: Gustave Flaubert de 1821 a 1857. Porto Alegre, RS: L\&PM (Original publicado em 1971).

Schneider, D. R. (2006). Liberdade e dinâmica psicológica em Sartre. Natureza Humana, 8(2), 283-314.

Schneider, D. R. (2009). Caminhos históricos e epistemológicos da psicopatologia: contribuições da fenomenologia e existencialismo. Cadernos Brasileiros de Saúde Mental, 1(2), 62-76.

Schneider, D. R. (2011). Sartre e a Psicologia Clínica. Florianópolis: Ed. da UFSC.

Schneider, D. R. (2017). Existe uma psicopatologia existencialista? In: Angerami, V. (Org). Psicoterapia Fenomenológica-Existencial. Belo Horizonte: Ed. Artesã.

Silva, A. P., Barros, C. R., Nogueira, M. L. M., \& Barros, V. A. (2007). "Conte-me sua história”: Reflexões sobre o método história de vida. Mosaico: Estudos em Psicologia, 1(1), 25-35.

Spíndola, T., \& Santos, R. da S. (2003). Trabalhando com a história de vida: percalços de uma pesquisa(dora?). Revista da Escola de Enfermagem da USP, 37(2), 119-126.

Spohr, B., \& Schneider, D. R. (2009). Bases epistemológicas da antipsiquiatria: a influência do Existencialismo de Sartre. Revista da Abordagem Gestáltica, 15(2), 115-125

Spohr, B. (2011). Lógica psiquiátrica e reforma em saúde mental. Mental, 9(17), 559-570.

Van Den Berg, J. H. (1981). O Paciente Psiquiátrico: esboço de psicopatologia fenomenológica $\left(4^{\circ}\right.$ ed). São Paulo: Mestre Jou. 
Jucimar Havrelhuk (Orcid: 0000-0001-59574103) é Psicólogo graduado pela Faculdade Guilherme Guimbala/Associação Catarinense de Ensino (Joinville/SC). Email: jucimarhavrelhuk@gmail.com

Fabíola Langaro (Orcid: 0000-0002-0691-7560) possui Graduação em Psicologia pela Universidade do Vale do Itajaí, Mestrado e Doutorado em Psicologia pela Universidade Federal de Santa Catarina. Atualmente é Docente do curso de Psicologia da Universidade do Sul de Santa Catarina (Unisul). Email: flangaro@hotmail.com

Recebido em 19.01.2018

Primeira Decisão Editorial em 03.05.2018

Aceito em 16.07.2018 